\title{
Foraging innovation in the guppy
}

\author{
KEVIN N. LALAND \& SIMON M. READER \\ Sub-Department of Animal Behaviour, Department of Zoology, University of Cambridge
}

(Received 31 March 1998; initial acceptance 11 May 1998;

final acceptance 1 September 1998; MS. number: 5837R)

\begin{abstract}
When novel behaviour patterns spread through animal populations, typically one animal will initiate the diffusion. It is not known whether such 'innovators' are particularly creative individuals, individuals exposed to the appropriate environmental contingencies, or individuals in a particular motivational state. We describe three experiments that investigated the factors influencing foraging innovation in the guppy, Poecilia reticulata. We exposed small laboratory populations of fish to novel foraging tasks, which involved exploration and problem solving to locate a novel food source. Experiments 1 and 2 found that (1) females were more likely to innovate than males, (2) food-deprived fish were more likely to innovate than nonfood-deprived subjects, and (3) smaller fish were more likely to innovate than larger fish. We suggest that the sex difference may reflect parental investment asymmetries in males and females. Experiment 3 found that past innovators were more likely to innovate than past noninnovators. Collectively, the results suggest that differences in foraging innovation in guppies are best accounted for by differences in motivational state, but, in addition, guppies may vary in their predisposition to innovate.
\end{abstract}

(C) 1999 The Association for the Study of Animal Behaviour

Animals often respond to novel circumstances, or physiological stresses, with new or modified behaviour patterns (Kummer \& Goodall 1985; Lee 1991), which we describe as innovation. We view as similar phenomena, and treat as examples of innovation, novel behaviour patterns such as the exploitation of new food sources, the development of new food-processing methods, and learning to use novel tools or technologies.

The best-known examples of animal innovation are behaviour patterns concerned with the extraction, preparation and processing of food. These include the washing of potatoes and wheat by Japanese macaques, Macaca fuscata (Kawai 1965), tool use in primates, particularly chimpanzees, Pan troglodytes (Goodall 1964; Beck 1980; McGrew 1994), and milk-bottle-top opening by British titmice, Parus spp. (Hinde \& Fisher 1951). Lefebvre et al. (1997) described 322 separate cases of feeding innovation in birds. In all such examples, a novel food source was utilized, or exploited more efficiently, as a result of the innovation. Other examples of innovation function in a social domain. For example, Goodall (1986) described a male chimpanzee that augmented his threat display by banging together empty kerosene cans, this behaviour coinciding with a dramatic rise in dominance status.

Correspondence: K. N. Laland, Sub-Department of Animal Behaviour, University of Cambridge, Madingley, Cambridge CB3 8AA, U.K. (email: knl1001@hermes.cam.ac.uk).
When a new behaviour spreads through a population, typically transmission follows from the innovation of a single individual. Innovation is regarded as an important component of behavioural plasticity, vital to the survival of individuals in species with generalist or opportunistic lifestyles (Lefebvre et al. 1997). However, despite being fundamental to several research programmes, little is known about which individuals form new behaviour patterns and what ecological variables influence innovation (Kummer \& Goodall 1985; Lee 1991). It is unclear whether animal innovation should be regarded as a personality trait (associated with particularly clever or creative individuals), a state-dependent variable (for example, foraging innovation may be driven by hunger), or whether it results from exposure to pertinent ecological stimuli (for instance, a sudden change in the environment).

Innovation is phylogenetically widespread, but species differ in innovative tendency (Thorpe 1956; Cousteau 1958; Cambefort 1981; Lefebvre et al. 1997), with greatest innovation associated with 'higher organisms' (Lloyd Morgan 1912; McDougall 1936) or animals with larger relative brain size (Wyles et al. 1983; Lefebvre et al. 1997). Innovation in animals is not often associated with clever or creative individuals, although there are exceptions (Köhler 1925; Wilson 1975). Fragaszy \& Visalberghi (1990) found no evidence that particular individuals in a captive group of capuchin monkeys, Cebus apella, possessed a 'characteristic propensity' to innovate. 
Experimental studies of rats, Rattus norvegicus, reveal that novel foraging behaviour can emerge in social transmission as a result of the accumulated effort of several individuals, and does not require a particular creative individual to initiate it (Laland \& Plotkin 1990).

Although compelling evidence is scarce, observations of natural animal populations suggest that particular classes of individuals may be prone to innovation. There is at least anecdotal evidence that innovators often differ from the remainder of the group in some characteristic, such as rank, age or sex. Katzir $(1982,1983)$ found that mid- to low-ranking jackdaws, Corvus monedula, were quicker to enter a novel space and exploit a novel food source than top-ranking birds. Primate studies appear to indicate that innovators are frequently on the outskirts of the social group (Kummer \& Goodall 1985). For instance, Sigg (1980) found that peripheral female hamadryas baboons, Papio hamadryas hamadryas, were significantly better at learning novel tasks than central females. However, Fragaszy \& Visalberghi (1990) presented novel tool use tasks to captive groups of capuchin monkeys and found that social vigilance inhibited innovation, those of 'vulnerable social status' being less likely to innovate.

Observations of primates suggest that foraging innovation may be more frequent among females than males, and among juveniles than adults (Itani 1965; Kawai 1965; Lee 1991). Young female chimpanzees are more likely to acquire a nut-cracking task than older males (Goodall 1986; Hannah \& McGrew 1987), and females more frequently use tools to extract high-quality resources such as invertebrates or nuts (McGrew 1979; Boesch \& Boesch 1981). Cambefort (1981) found that juvenile chacma baboons, Papio hamadryas ursinus, were more likely to discover and exploit novel foods, while Kummer \& Goodall (1985) described a number of chimpanzee innovations that emerged during infancy, and reported that occasionally infants, but never adults, will taste a novel food. It is commonly suggested that one of the functions of infant play and exploration is to facilitate the emergence of new behaviour (Mainardi 1980; McFarland 1981).

To date, virtually all relevant data on innovation in animals come from observations of natural populations, which frequently have an anecdotal quality. In several instances, the novel behaviour has been observed only once, and in a single individual (Kummer \& Goodall 1985). Many such reports require clarification before it can be certain that the behaviour concerned is more than a random or accidental event, and that it serves the function attributed to it. Moreover, in the field it is not possible to control for correlated variables. While there are numerous experimental studies demonstrating that particular individuals, or species, are capable of solving a novel problem, each of which could be regarded as an example of innovation, the vast majority of such experiments have not investigated within-species variation in problem-solving ability, and there are surprisingly few experimental studies of problem solving that focus on sex, age or dominance rank differences (Hutt 1973). What is needed is a systematic experimental investigation of how innovation occurs in controlled animal populations, in order to integrate field, laboratory and theoretical findings.

We investigated the innovative tendency of guppies, Poecilia reticulata, in laboratory experiments. The innovation involved exploration and problem solving to locate a novel food source. Guppies are an excellent model system for research into animal innovation for several reasons. First, social transmission of foraging information has been clearly demonstrated in guppies (Laland \& Williams 1997), and it would be valuable to establish which individuals are most likely to generate the foraging innovations. Second, guppies vary in their tendency to inspect unfamiliar predators (Magurran et al. 1993), which may reflect variation in a more general response to novel situations, and thereby influence foraging innovation. Third, there is a substantial behavioural literature on guppies. Fourth, guppies have a number of practical advantages. They are easy and inexpensive to keep in small populations as a consequence of their small size and simple feeding requirements. This means that large numbers of experimental populations can be established, presented with novel foraging tasks, and monitored to determine the characteristics associated with behavioural innovation. In the wild, the guppy feeds on several prey types in varied locations (Dussault \& Kramer 1981), and prefers to live in groups of conspecifics (Magurran et al. 1995). Our experimental paradigm imitated a scenario in which individuals move away from the shoal to locate a novel food source. The design allowed individual differences to be examined while allowing interaction between shoal members and without subjecting them to the stress of isolation. In experiments 1 and 2 , shoals of guppies were presented with a novel foraging task, and the sex, size and hunger level of the first fish to complete the task successfully was noted. In experiment 3 we examined whether certain individuals have a particular propensity to innovate.

\section{EXPERIMENT 1: SEX AND HUNGER LEVEL}

This experiment investigated whether the likelihood that an individual guppy will innovate to locate and exploit a novel food source is influenced by its sex or hunger level. Several experimental populations were established, each containing equal numbers of males and females, and equal numbers of food-deprived and nonfood-deprived fish. Each population was presented with a novel foraging task, and the sex and hunger level of the first fish to complete the task was recorded.

\section{Methods}

We established four experimental populations of 16 fish, each containing four food-deprived and four nonfood-deprived fish of each sex. Additional fish of each sex and hunger-level category were kept in holding tanks. Each of the novel foraging tasks involved swimming a simple maze to locate a food source, which consisted of an unfamiliar but desirable food accessible from an unfamiliar feeder. We presented each population with a 
foraging task by inserting the maze apparatus into the experimental tank, and recording the category of the first fish to complete the task. This fish was then removed and replaced with a fish from the holding tank of the same sex, hunger level and size. After a 'cooling off' period, the newly established population was then presented with a different foraging task, and again the innovator recorded and removed. By repeating this procedure we were able to simulate large numbers of independent populations. We were able to employ statistical analyses (described below) to investigate whether the trials were independent, and whether the newly introduced fish behaved equivalently to the originals.

\section{Subjects and apparatus}

We used 41 adult males and 59 adult females. A further four males and one female were removed from the experiment when they followed the 'innovator' to the food source. Domestic rather than wild guppies were chosen since individuals can be recognized by their distinctive coloration. Each fish was drawn for purposes of identification. Males weighed $0.60 \pm 0.049 \mathrm{~g}(\bar{X} \pm \mathrm{SE})$ and females $0.60 \pm 0.079 \mathrm{~g}$; the subjects were deliberately chosen so that the sexes did not differ significantly in mass. We purchased the fish used in all three experiments from Neil Hardy Aquatics, London.

Prior to the experiment, subjects were housed in holding tanks measuring $90 \times 30 \times 33 \mathrm{~cm}$ and fed on standard tropical fish flaked food. The experimental tanks measured $60 \times 30 \times 33 \mathrm{~cm}$. All tanks were maintained at $25^{\circ} \mathrm{C}$, and had a water depth of $30 \mathrm{~cm}$. The fish were on a 12:12 h light:dark schedule, with lights on at 0700 hours; additional red lights were on continuously, so that the switch in lighting was less disturbing to the fish. Each task involved swimming through a maze apparatus, placed $10 \mathrm{~cm}$ from the end of the tank, and into a goal zone containing a floating feeder. The mazes were opaque white PVC dividing partitions, each containing a hole through which the fish could swim to the other end of the tank. A partition $10 \mathrm{~cm}$ in front of the maze allowed the apparatus to be set up while excluding the fish, with the raising of this partition signifying the beginning of a trial. A second partition slid directly behind the maze, being pushed down completely to close the hole once a trial had ended. The goal zone contained a concealed floating feeder of red plastic $30 \mathrm{~mm}$ in diameter and $6 \mathrm{~mm}$ deep. Small quantities (approximately four items) of freeze-dried bloodworm (Chironomus spp.) were placed in these feeders. Bloodworm was a novel food item for these fish.

In task 1 (Fig. 1a), the maze apparatus was a partition with a square $(5 \times 5 \mathrm{~cm})$, centrally located hole at the bottom of the tank. In task 2 (Fig. 1b), the maze was a partition with a plastic, cylindrical, upright tunnel (height $6.5 \mathrm{~cm}$, entrance diameter $8 \mathrm{~cm}$ ) covered in dark green cellophane in front of a square, centrally located $5 \times 5 \mathrm{~cm}$ hole at the top of the partition. Here, the fish had to swim up the tunnel and then across through the hole to reach the food source. In task 3 (Fig. 1c), the maze apparatus in task 2 was turned upside-down so that fish had to swim downwards and then across through a hole
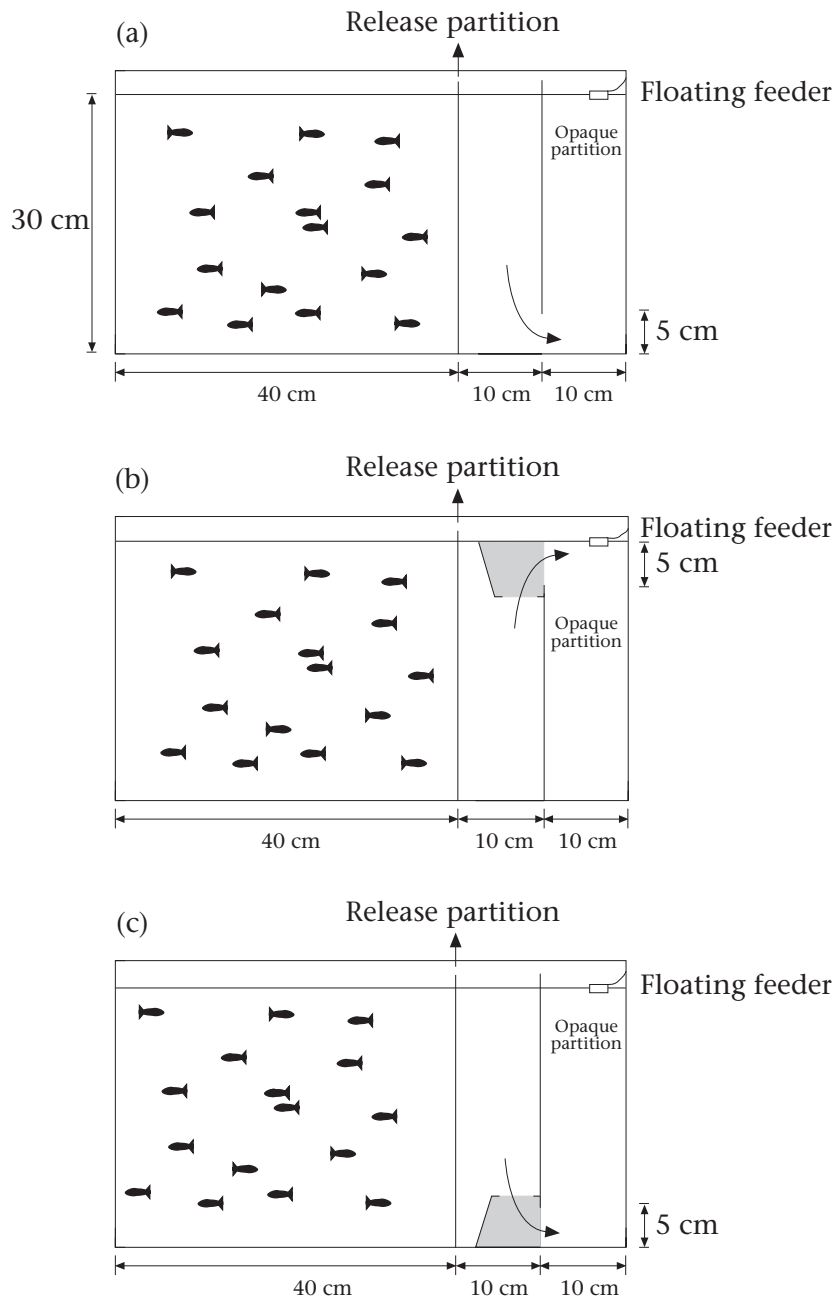

(d)

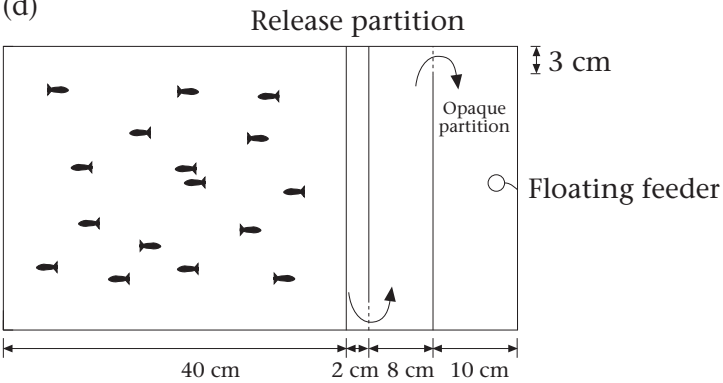

Figure 1. The foraging tasks. (a) Side view of the maze in task 1. (b) Side view of the maze in task 2. (c) Side view of the maze in task 3. (d) Plan view of the maze in task 4. The shaded areas indicate dark green, plastic tunnels. Curved arrows indiate the route taken by fish to complete the task. The directions in which the opaque release partitions are removed are indicated by straight arrows.

at the bottom of the tank. Pilot studies suggested that these three tasks were of increasing difficulty to the fish, judging by the average time to complete them.

\section{Experimental procedure}

The subjects were initially kept in four separately housed groups (food-deprived females, nonfood-deprived 
females, food-deprived males and nonfood-deprived males). The sexes were separated to avoid any further hunger differences arising through the differing competitive foraging abilities of males and females. Fooddeprived fish were given no food for 4 days prior to testing, a procedure that did not cause any visible signs of ill effects or stress before, during or after testing. Nonfood-deprived fish were fed daily with standard tropical fish flaked food. One day prior to testing, the four populations of 16 guppies containing equal numbers from each group were created in the experimental tanks.

The testing procedure was as follows. A partition was added at one end of the experimental tank and pushed along the tank until there was sufficient space to set up the apparatus behind it. We then inserted the apparatus into the tank, finally adding the feeder and bloodworm $30 \mathrm{~s}$ before the start of a trial, which we began by gently withdrawing the partition from the tank. Once a fish had entered the goal zone, or 600 s had elapsed, we closed the entrance and terminated the trial. The successful fish was allowed to feed, its category noted, and it was then removed from the experiment. All apparatus was removed from the tank. We chose a fish of the same category and of a similar size from the appropriate holding tank, drew it for identification purposes, and then added it to the population. Any fish that followed the first fish into the goal zone before the hole could be closed were also removed and replaced with fish of the same category. The next task began at the opposite end of the tank 40 min after the previous trial, and 30 min after the new fish had been added. Task type and position were alternated, so a population received the same task in the same position only once every $4 \mathrm{~h}$. This was designed to reduce the opportunity for subjects to learn to complete the task by observing conspecifics. In total 36 populations were established in this manner.

At the end of the experiment all subjects were weighed. Fish were caught in a mesh net, dried with absorbent paper, and placed into a beaker of water on a tared balance.

\section{Results and Discussion}

Figure 2 shows the results. In 27 of the 36 populations the first fish to complete the task was a female (chi-square test: $\left.\chi_{1}^{2}=9.00, P<0.005\right)$, while in 25 of the 36 populations it was food deprived (chi-square test: $\chi_{1}^{2}=5.44, P<0.025$ ). No interaction was found between sex and hunger level (chi-square test: $\chi_{1}^{2}=1.09$, NS). No effect of task, tank or task location was found (chi-square tests: $\chi_{2}^{2}=2.00, \mathrm{NS}$; $\chi_{3}^{2}=0.22$, NS; $\chi_{1}^{2}=0.44$, NS; respectively).

The experiment provides clear evidence that females and food-deprived guppies are more likely to innovate to locate a novel food source than males and nonfooddeprived fish, respectively. We suggest explanations for these findings in the General Discussion. However, the sex difference cannot be explained as resulting from a size difference between the sexes. In natural populations of guppies, males are typically smaller than females (Magurran et al. 1995). In this experiment, by deliberately choosing large males and small females, and equating the
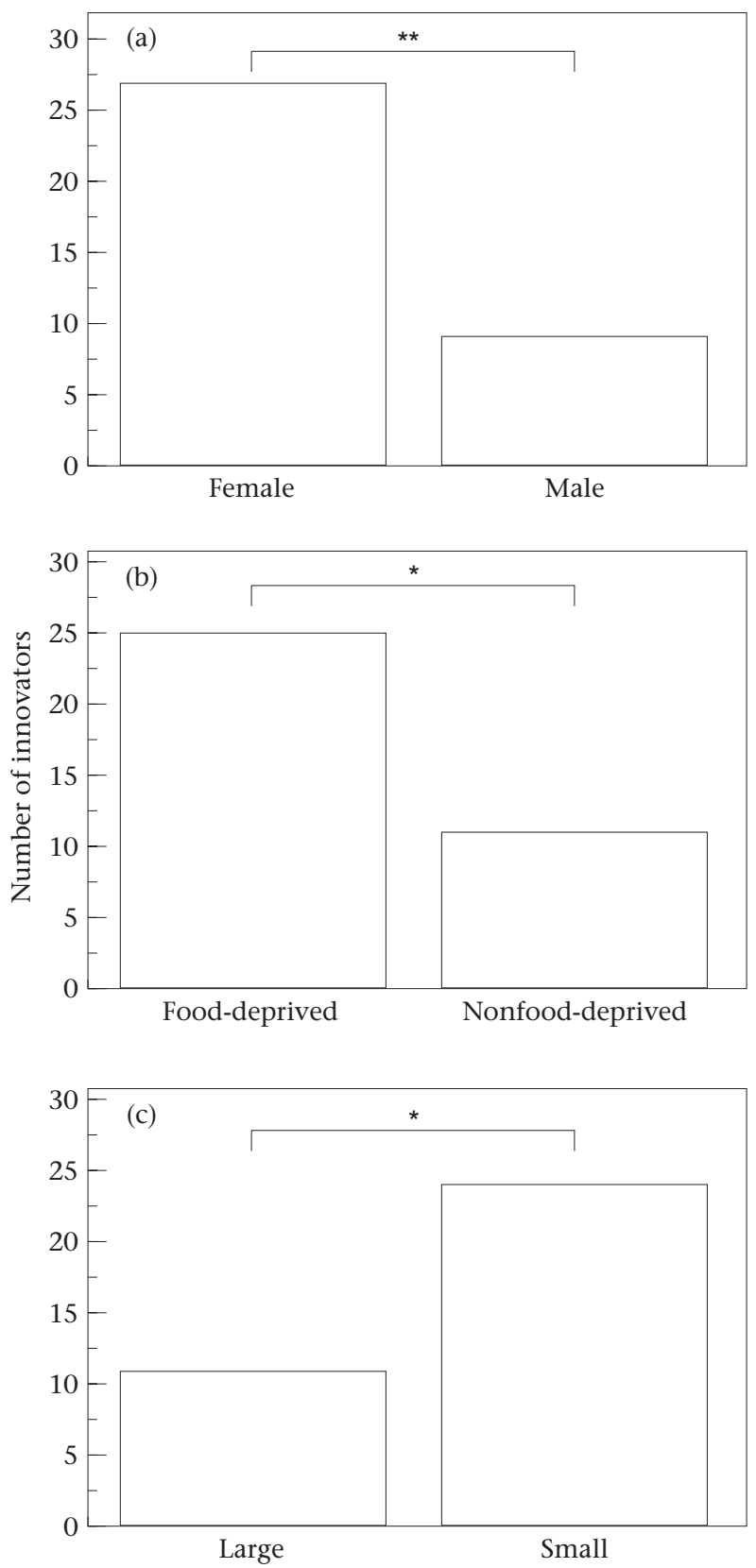

Figure 2. The number of innovators that were (a) female or male, (b) food-deprived or nonfood-deprived, or (c) large or small. We defined an innovator as the first individual in a population to complete a novel foraging task. ${ }^{*} P<0.05 ;{ }^{*} P<0.01$.

sexes for mass, we were able to eliminate mass as a confounding variable. Experiment 2 addressed the effects of mass on the likelihood of innovation. It is also implausible to explain the sex difference as resulting from a difference in activity level between the sexes. First, there was no evidence for males being less active than females, and although activity levels were not recorded here, pilot studies in our laboratory have found greater levels of activity among males than females. Griffiths \& Magurran (1998) also reported that male guppies appeared more active than females. Second, individuals of both sexes spent a great deal of time at the entrance, or edges, of the 
maze, probably because they could smell the food. However, it was notable that females were both more rigorous in their search for the holes in the mazes, and more likely to swim through the holes when they encountered them, than were males.

The separate populations in this experiment are not truly independent, since our method dictates that some of the same individuals will be in more than one population. Given the large number of populations required for this experiment, and the enormous number of experimental subjects that this would require if the populations were truly independent, we feel that our procedure for simulating independent populations is a sensible compromise. However, our method might be vulnerable to at least two kinds of bias. First, pseudoreplication may result in the newest fish being artificially more likely to be selected as an innovator. Second, stress from the recent transport of the newest fish may result in it being artificially less likely to be selected as an innovator. We addressed these issues statistically by investigating the performance of the fish most recently placed in the tank, and comparing it with the performance of fish in the same category. We found that the fish most recently placed in the tank were no more or less likely to be innovators than other fish of the same category (chisquare test: $\left.\chi_{3}^{2}=3.60, \mathrm{NS}\right)$. Our finding that there was no interaction between sex and hunger level means that the statistical significance of the results cannot be attributed either solely to the innovation of the food-deprived females, or to the persistence in the tank (lack of innovation) of the nonfood-deprived males. The observation that there was no effect of tank implies that the findings are not an artefact of particular individuals remaining inactive in particular populations. The independence of the trials is further demonstrated by a comparison of the observed and expected proportion of innovators among the founder or original fish in each population (chi-square test: $\chi_{3}^{2}=0.38, \mathrm{NS}$ ). For any given trial, the probability that an innovator of each category would be an original is given by the proportion of the four fish in that category that are originals immediately prior to that trial. By summing across trials in each tank, and across all four tanks, we can compute exact expectations for the number of original fish in each category innovating, and compare those with the observed number of innovators. Collectively, these findings suggest that there is no pseudoreplication, and that it is reasonable to treat the trials as independent.

\section{EXPERIMENT 2: BODY SIZE}

Experiment 2 investigated whether the likelihood that an individual guppy will innovate to locate and exploit a novel food source is influenced by its size. Using the same procedure as in experiment 1 , several experimental populations were established, each containing equal numbers of males and females, and equal numbers of small and large fish. Once again, we presented each population with a novel foraging task, and recorded the sex and weight of the first fish to complete the task. Mass is tightly correlated with age in guppies, so we did not attempt to distinguish between these two factors. In contrast to experiment 1 , here the sexes differed in mean weight, males being lighter than females, as is the situation in the wild.

\section{Methods}

The experimental design was the same as in experiment 1 , except that none of the fish was food deprived, but subjects were allocated to two size categories, small and large. Four experimental populations of 16 fish were established, each containing four small and four large fish of each sex. Additional fish of each sex and size category were kept in holding tanks.

\section{Subjects and apparatus}

We used 42 male and 56 female guppies. A further four males and four females were removed from the experiment when they followed the 'innovator' to the food source. Experimental subjects were chosen to maximize the range of sizes taking part. Females $(\bar{X} \pm \mathrm{SE}=0.49 \pm 0.023 \mathrm{~g})$ were significantly larger than males $\left(0.43 \pm 0.016 \mathrm{~g}\right.$; independent $t$ test: $t_{96}=1.98$, $P=0.025$, one-tailed). Male fish greater than $0.43 \mathrm{~g}$ and female fish greater than $0.47 \mathrm{~g}$ were defined as large fish, these weights representing the median weights for each sex among all of the 170 fish in our experimental and holding tanks. Large fish $(\bar{X} \pm \mathrm{SE}=0.56 \pm 0.019 \mathrm{~g})$ were significantly larger than small fish $(0.37 \pm 0.012 \mathrm{~g}$; independent $t$ test: $\left.t_{96}=9.13, P<0.0001\right)$. The apparatus and mazes were identical to that used in experiment 1.

\section{Experimental procedure}

The subjects were split into two separately housed groups, males and females. The day before testing, we set up four populations of 16 fish in the experimental tanks. These populations contained equal numbers of each sex, with half the fish chosen from among the largest available, and half from among the smallest available. We initially categorized the size of subjects by eye since we felt that weighing the fish before testing may stress them and affect the results. Therefore, unlike the fooddeprivation category in experiment 1 , the size classes were not housed separately prior to the tests.

We tested each population for its ability to find a hidden food source as in experiment 1 . The successful fish were replaced with another of the same sex, and matched in size as closely as possible. At the end of each trial the successful fish (and any followers) were weighed. In total 35 populations were established, and tested, in the manner described for experiment 1 . After the experiment, all remaining fish in the experimental and holding tanks were weighed. This allowed us to determine the median weight for each sex. Subjects above the median were categorized as large, and those below the median as small. No errors were made in the size categorization of subjects by eye. Since the sexes could be distinguished easily and the size classification was made by weight, it was not necessary to recognize individuals in order to determine the category of successful fish. 


\section{Results and Discussion}

Figure $2 \mathrm{c}$ shows the results. In 25 of the 35 populations the first fish to complete the task was a female (chi-square test: $\left.\chi_{1}^{2}=6.43, P<0.025\right)$, while in 24 of the 35 populations it was small (chi-square test: $\chi_{1}^{2}=4.83, P<0.05$ ). No interaction was found between sex and size (chi-square test: $\chi_{1}^{2}=0.85$, NS). No effect of task, tank or task location was found (chi-square tests: $\chi_{2}^{2}=2.97, \mathrm{NS} ; \chi_{3}^{2}=0.54, \mathrm{NS}$; $\chi_{1}^{2}=0.03$, NS; respectively).

This experiment provides clear evidence that females and smaller guppies are more likely to innovate to locate a novel food source than males and larger fish, respectively. Since males were substantially smaller than females, the sex difference found in this experiment cannot be explained as resulting from mass differences since small fish were more, not less, likely to locate the goal zone than large fish. Experiment 1 examined the unnatural situation where males and females were of similar size, but the results of experiments 1 and 2 combined allow us to predict that sex differences in foraging innovation may exist in natural guppy populations. Moreover, in this experiment the male and female fish were of similar ages, which suggests that an age difference is unlikely to account for the difference between the sexes in experiment 1 . We raise a number of possible explanations in the General Discussion for the observation that smaller individuals (or juveniles) may be more likely to be innovators than larger individuals (or adults).

In this experiment, because we did not note the identity of each individual, we cannot determine whether those fish most recently added to the tank were more or less likely than other fish of the same category to innovate. However, the results of experiment 1, which used an identical procedure to create artificial populations, implies that it is probably reasonable to treat the populations in experiment 2 as independent.

\section{EXPERIMENT 3: ARE THERE INNOVATOR FISH?}

Experiments 1 and 2 revealed differences in the propensities of guppies to innovate in order to locate novel food sources. These findings raise the possibility that there may be variation in the natural proclivities of individual fish to innovate, that is, that there may be 'personality' differences which incline some individuals to behave in an innovative manner. We reasoned that if such trait or 'personality differences' existed, then guppies identified as 'good' or 'bad' innovators in one novel foraging task would show a similar level of innovation in a second foraging task.

However, as guppies are shoaling fish, some fish identified as 'innovators' might be fish that followed other fish into the goal zone rather than being 'innovators' themselves. Were this to occur, such fish would dilute any differences in innovative tendency between the fish identified as 'past innovators' and 'past noninnovators', leading to a type 2 error. To address this problem, we presented fish in this experiment with three foraging tasks, the first two identifying fish that had innovated (and failed to innovate) twice, and the third testing whether 'twice-past innovator' fish were faster than 'twice-past noninnovators'. We reasoned that selecting for innovators and noninnovators twice would reduce any confounding effect caused by following.

\section{Methods}

\section{Subjects and apparatus}

We used 24 male and 24 female guppies. These subjects initially composed two populations of 24 fish, each with 12 males and 12 females. After the selection procedure described below, a single population of 16 fish, with eight males and eight females, took part in the final test. Fish were housed in standard aquaria measuring $60 \times 30 \times 33 \mathrm{~cm}$, maintained at $25^{\circ} \mathrm{C}$, and fed on freezedried bloodworm or standard tropical fish flaked food. Innovation tests were conducted using the mazes shown in Fig. 1a, c, and the two-partition maze shown in Fig. 1d.

\section{Procedure}

Subjects were placed in two tanks to make two populations each of 24 fish, with equal numbers of males and females. The distinctive colour markings of each fish were noted so that it could be identified. On day 1 all fish were presented with task 1 (Fig. 1a) for $20 \mathrm{~min}$ and their time to complete the task noted. To ensure that the subjects received equivalent reinforcement, we ensured that all fish had completed the task and that they were allowed to feed until they were no longer interested in food. From each tank the six fish of each sex that completed the task fastest were labelled 'innovators'. The innovators from the two populations were placed together in a single tank, with the noninnovators placed in a second tank. These fish had undergone the first round of selection for innovators. For the next 5 days all fish were fed to satiation three times daily. On day 6, fish in both populations were then retested using task 4 (Fig. 1d), and again classified as innovators or noninnovators. Eight of the 12 innovators from the population of past innovators and eight of the 12 noninnovators from the population of past noninnovators were placed together in a single tank, with the rest of the fish removed from the experiment. In this second round of selection for innovators/noninnovators, we matched innovators and noninnovators for size and sex as far as possible, to eliminate these factors as confounding variables. Once again the fish in this population were fed to satiation three times daily, for 5 days. Finally on day 11 , we presented the fish in this population with task 3 (Fig. 1c), for $30 \mathrm{~min}$, and recorded the times at which each fish entered the goal compartment.

\section{Results and Discussion}

Past double innovators: (latency: $\bar{X} \pm \mathrm{SE}=923 \pm 165 \mathrm{~s}$ ) completed the task significantly faster than past double noninnovators $(1399 \pm 174 \mathrm{~s}$; paired $t$ test: $t_{7}=2.20, P<0.05$, one-tailed). There were no significant differences in mass between past double innovators 


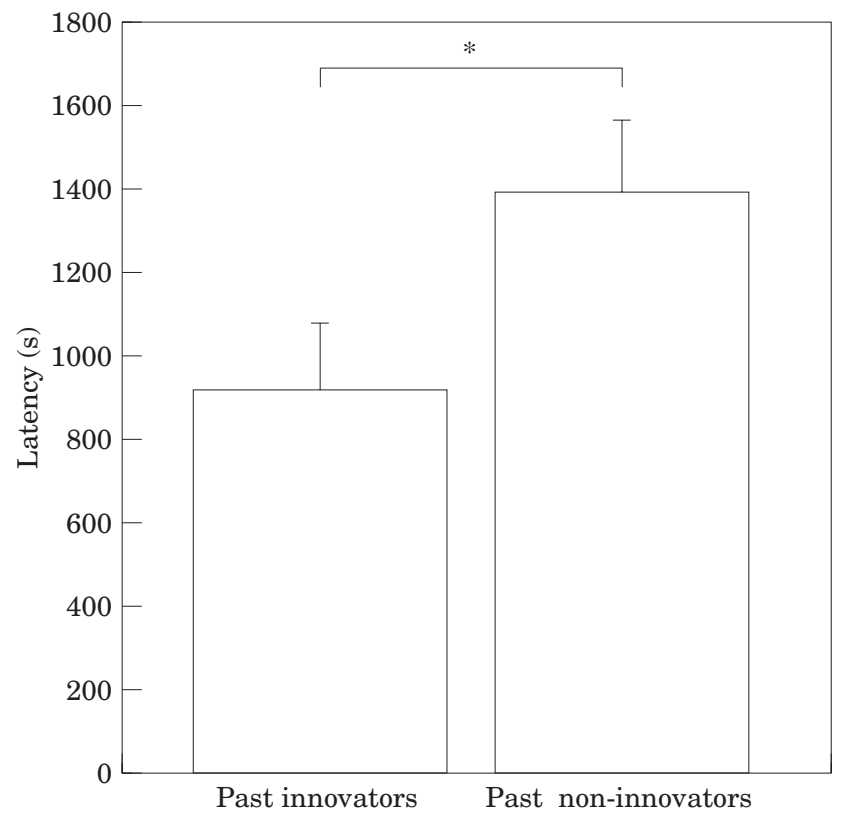

Figure 3. The latency of past innovators and past noninnovators to complete a novel foraging task. Past innovators had undergone two rounds of selection, where we chose those guppies quickest to complete two different novel foraging tasks. Past noninnovators were chosen as those completing these tasks the slowest. ${ }^{*} P<0.05$.

$(\bar{X} \pm \mathrm{SE}=0.33 \pm 0.03 \mathrm{~g})$ and past double noninnovators $(0.37 \pm 0.03 \mathrm{~g})$, eliminating mass differences as an alternative explanation (paired $t$ test: $t_{7}=1.22$, NS). Among fish taking part in the final test, there was a significant correlation between their performance on the first and final maze tasks (Spearman rank correlation: $r_{\mathrm{S}}=0.445$, $\left.t_{14}=1.86, P<0.05\right)$.

Guppies typically form loose shoals, and although they influence each other's movements, they do not typically school tightly to swim as a collective unit. In this experiment, the fish tended to swim the mazes in ones and twos, rather than all together. Thus there is no suggestion that most of the individuals classified as innovators were actually just following an original innovator. Although there was almost certainly some following taking place, this would serve only to weaken any differences between the fish categorized as past double innovators and past double noninnovators. The equal numbers of each sex, and the procedure of feeding to excess between tests, render as implausible explanations for the difference between past innovators and noninnovators in terms of sex or hunger. The simplest explanation for the findings of this experiment is that guppies express 'personality' differences in their natural proclivity towards foraging innovation.

\section{GENERAL DISCUSSION}

Experiments 1 and 2 identified three factors that influence foraging innovation: that is, sex, hunger level and size. In summary, females were more likely to innovate than males, food-deprived fish were more likely to innovate than nonfood-deprived subjects, and smaller fish were more likely to innovate than larger fish. Collectively, these experiments suggest that motivational state is the principal factor underlying guppy foraging innovation. The proverb 'necessity is the mother of invention' rings true for guppies, with the principal foraging innovators being those fish driven to seek food by hunger, or the high metabolic costs of growth or pregnancy. These findings also support the claim (Laland \& Plotkin 1990) that particularly creative or clever individuals are not necessary for innovation to occur.

It is perhaps not surprising that food-deprived fish are more likely to innovate to locate food, since they are more active and exploratory in their behaviour, better motivated to find food, and more likely to take risks to locate food (Godin \& Smith 1988; Milinski 1993). The sex difference in guppy foraging innovation, however, cannot adequately be explained in terms of differences between the sexes in size, age or activity. We suggest that this sex difference can most parsimoniously be accounted for by using one of the tenets of behavioural ecology, to provide an explanation in terms of parental investment patterns. Where males provide only sperm (most mammals, but also many fish), male reproductive success is mainly limited by access to females, while female reproductive success is mainly limited by access to resources (Davies 1991). Guppies are viviparous, with no postnatal parental care, which means that female parental investment is considerably greater than that of males, whose contribution is restricted to sperm production and fertilization. As the more food resources a female guppy can gather, the more offspring she can produce (Dussault \& Kramer 1981; Constanz 1989; Reznick \& Yang 1993), there will be a high premium on female foraging innovation. In contrast, males almost certainly maximize their fitness by devoting a greater proportion of their time and energy to mating, with a corresponding smaller proportion allocated to foraging, than females. Observations from the laboratory, where, on average, a male displays to females seven times in 5 min (Farr \& Herrnkind 1974), and from the wild, where females receive a sneaky mating attempt every minute (Magurran $\&$ Seghers 1994), certainly suggest males prioritize sex. As, in guppies, adult females are virtually always pregnant, a simple proximate version of this explanation is that females are hungrier because of higher metabolic needs. Alternatively, divergent selection pressures resulting from asymmetrical parental investment may have produced a predisposition favouring greater exploratory behaviour in females, irrespective of their hunger levels. Experiments comparing foraging innovation in virgin and pregnant adult females would address this issue. Exploratory behaviour is often both energetically costly and carries increased predation risks (Hart 1993; Milinski 1993), yet adult female guppies are apparently prepared to accept these costs in order to find food. The fact that, in fish, female fecundity increases with accelerating returns with increasing body length, while a male's ability to obtain matings probably increases linearly or with diminishing returns with body length (Sargent \& Gross 1993), means 
that a conservative foraging strategy is less likely to be adaptive in females than in males.

Parental investment asymmetries are common in nature (Davies 1991), and consequently we anticipate that for many vertebrate species there may be greater fitness advantages associated with female than with male innovation of feeding behaviour. Conversely, male innovation may be devoted to traits that are likely, directly or indirectly, to increase rates of copulation. There is some circumstantial evidence in support of this hypothesis from observations of natural and captive populations of chimpanzees. Kummer \& Goodall (1985) described examples of male chimpanzees that rose earlier than other chimps to lead females (by shaking branches) away from others to copulate secretly; that got up early to perform charging displays, or used branches and empty paraffin cans to augment displays (behaviour patterns that corresponded with a rise in the dominance hierarchy); that developed a new and effective courtship display by flipping his upper lip over his nostrils; and that used a stick to inspect the genital area of a female. In male chimpanzees there is a significant correlation between dominance and frequency of matings. These authors reported no corresponding cases of female chimpanzee innovation resulting in access to mates or a rise in dominance status.

There are several explanations for the observation that smaller individuals (or juveniles) may be more likely to be innovators than larger individuals (or adults). First, a relatively poor ability at scramble competition for food, compared with larger conspecifics, may drive small fish to gain access to food in novel ways (Krause 1994), small fish perhaps being more prepared to explore and leave the group, risking increased predation, in order to take advantage of reduced competition (Grant \& Noakes 1987). An earlier study of ours found that smaller guppies were out-competed for food by larger individuals (unpublished data). As poor competitors, smaller fish may simply have been hungrier than larger fish, and the results of experiment 2 may be explained as resulting from hunger rather than size differences. Once again, these issues can be addressed with careful experimentation.

A second explanation for the difference between the sizes is that, if they benefit more from rapid growth than larger individuals, smaller fish should be willing to accept a greater risk to forage (Grant \& Noakes 1987). Small guppies may have higher metabolic costs associated with more rapid growth, as in other fish species (Oikawa \& Itazawa 1992; Pedersen 1997), and so need to acquire food at elevated rates relative to large fish. Third, large fish may be able to avoid risky situations because of their higher energy reserves. Mikheev et al. (1994) found that small juvenile salmon, Salmo salar, which have smaller energy reserves, left safe refuges to search for food more rapidly than larger juveniles. Fourth, if conspicuousness and vulnerability to visual predators increase with body size, increased wariness with increasing body size should be favoured (Grant \& Noakes 1987). Finally, in primates at least, juveniles may have more time for exploration as a consequence of parental care (Kummer \& Goodall
1985), or a greater natural propensity for innovative behaviour, relative to older and larger conspecifics. Increased rates of innovation amongst juvenile primates and cetaceans have been described in the laboratory (Cambefort 1981) and in field observations (e.g. Kawai 1965; Weinrich et al. 1992).

Experiment 3, which took steps to remove the confounding effects of following and motivational state, found that past innovators were more likely to innovate than past noninnovators, indicative of an innovative 'personality' expressed by some fish. At this stage it is not clear whether such differences reflect variation in mental abilities (e.g. intelligence, creativity), sociality (e.g. a tendency to stay with or leave the group), boldness (e.g. a tendency to approach unfamiliar objects), exploratory behaviour (e.g. a tendency to investigate unfamiliar spaces), some other factor, or some combination of these factors. None the less, it is interesting, and perhaps surprising, that we find evidence for innovative individuals in a species not particularly renowned for its intelligence or problem-solving capabilities.

In this paper we have repeatedly referred to the solution of the maze tasks as 'innovation'. It might be objected that the swimming of a maze has little in common with, for example, the kind of innovation shown by Imo, the potato-washing macaque, or those chimpanzees studied by Köhler (1925) thought to have solved complex problems through 'insight'. Such objectors might prefer to reserve the term 'innovation' for qualitatively new or cognitively demanding tasks. In our view this would be a mistake. A broad definition is justified, given the primitive state of knowledge of animal innovation. The key characteristic of innovation is the introduction of a novel behaviour pattern into a population's repertoire, and it would be unwise to insist that in the process the innovator must express a previously unobserved motor pattern, or exhibit some unusual level of intelligence. For instance, there is no reason to believe that Köhler's chimpanzees moved their bodies in ways they had never moved before, while there is reason to believe that food washing is common in macaques (Visalberghi \& Fragaszy 1990; Galef 1992), which means the innovation shown by Imo involved the application of a familiar behaviour pattern to a novel food source. Moreover, subjective judgements of intelligence may be prejudiced by assumptions based on phylogenetic proximity to humans. For the guppies, the term innovation refers to a combination of exploration and problem solving. The innovator was the first individual to solve the maze task in order to exploit a novel food source. Other experiments carried out in our laboratory, in which populations of guppies were exposed to repeated trials of maze tasks, have found evidence for the transmission of this acquired foraging information between individuals, and of its diffusion through the population (Laland \& Williams 1997; unpublished data). Thus the kind of innovation expressed by our guppies can indeed introduce novel behaviour patterns into a population. There is reason to believe that the same parental investment explanation that we have proposed to account for differences in guppy foraging innovation may equally apply to 
primate innovation. Making premature distinctions jeopardizes the ability to see genuine relationships between different kinds of novel behaviour. In time, it may prove valuable to make distinctions between different classes of innovation, but such distinctions are best based on empirical data.

\section{Acknowledgments}

This work was supported by a Royal Society University Research Fellowship to K.N.L. and a BBSRC studentship to S.M.R.

\section{References}

Beck, B. B. 1980. Animal Tool Behavior: The Use and Manufacture of Tools by Animals. New York: Garland.

Boesch, C. \& Boesch, H. 1981. Sex differences in the use of natural hammers by wild chimpanzees: a preliminary report. Journal of Human Evolution, 10, 585-593.

Cambefort, J. P. 1981. A comparative study of culturally transmitted patterns of feeding habits in the chacma baboon Papio ursinus and the vervet monkey Cercopithecus aethiops. Folia Primatologica, 36, 243-263.

Constanz, G. D. 1989. Reproductive biology of Poeciliid fishes. In: Ecology and Evolution of Livebearing Fishes (Ed. by G. K. Meffe \& F. F. Snelson), pp. 33-50. Princeton, New Jersey: Prentice Hall.

Cousteau, J. Y. 1958. The Silent World. Harmondsworth, U.K.: Penguin.

Davies, N. 1991. Mating systems. In Behavioural Ecology: An Evolutionary Approach. 3rd edn (Ed. by J. R. Krebs \& N. B. Davies), pp. 263-294. Oxford: Blackwell.

Dussault, G. V. \& Kramer, D. L. 1981. Food and feeding behaviour of the guppy, Poecilia reticulata (Pisces: Poeciliidae). Canadian Journal of Zoology, 59, 684-701.

Farr, J. A. \& Herrnkind, W. F. 1974. A quantitative analysis of social interaction of the guppy, Poecilia reticulata (Pisces: Poeciliidae) as a function of population density. Animal Behaviour, 22, 582-591.

Fragaszy, D. M. \& Visalberghi, E. 1990. Social processes affecting the appearance of innovative behaviours in capuchin monkeys. Folia Primatologica, 54, 155-165.

Galef, B. G., Jr. 1992. The question of animal culture. Human Nature, 3, 157-178.

Godin, J. G. J. \& Smith, S. A. 1988. A fitness cost of foraging in the guppy. Nature, 333, 69-71.

Goodall, J. 1964. Tool using and aimed throwing in a community of free living chimpanzees. Nature, 201, 1264-1266.

Goodall, J. 1986. The Chimpanzees of Gombe. Cambridge, Massachusetts: Belknap.

Grant, J. W. A. \& Noakes, D. L. G. 1987. Escape behaviour and use of cover by young-of-the-year brook trout, Salvelinus fontinalis. Canadian Journal of Fisheries and Aquatic Sciences, 44, 1390-1396.

Griffiths, S. W. \& Magurran, A. E. 1998. Sex and schooling behaviour in the Trinidadian guppy. Animal Behaviour, 56, 689693.

Hannah, A. C. \& McGrew, W. C. 1987. Chimpanzees using stones to crack open oil palm nuts in Liberia. Primates, 28, 31-46.

Hart, P. J. B. 1993. Predation risk and feeding behaviour. In: Behaviour of Teleost Fishes. 2nd edn (Ed. by T. J. Pitcher), pp. 253-284. London: Chapman \& Hall.

Hinde, R. A. \& Fisher, J. 1951. Further observations on the opening of milk bottles by birds. British Birds , 44, 393-396.
Hutt, S. J. 1973. Constraints upon learning: some developmental considerations. In: Constraints on Learning: Limitations and Predispositions (Ed. by R. A. Hinde \& J. Stevenson-Hinde), pp. 457-467. London: Academic Press.

Itani, J. 1965. On the acquisition and propagation of a new food habit in the troop of Japanese monkeys at Takasakiyama. In: Japanese Monkeys: A Collection of Translations (Ed. by K. Imanishi \& S. A. Altmann), pp. 52-65. Edmonton: University of Alberta Press.

Katzir, G. 1982. Relationship between social structure and response to novelty in captive jackdaws, Corvus monedula L., I. Response to novel space. Behaviour, 81, 231-264.

Katzir, G. 1983. Relationship between social structure and response to novelty in captive jackdaws, Corvus monedula L., II. Response to novel palatable food. Behaviour, 87, 183-208.

Kawai, M. 1965. Newly acquired pre-cultural behavior of the natural troop of Japanese monkeys on Koshima inlet. Primates, 6, 1-30.

Köhler, W. 1925. The Mentality of Apes. New York: Harcourt \& Brace.

Krause, J. 1994. The influence of food competition and predation risk on size-assortative shoaling in juvenile chub (Leuciscus cephalus). Ethology, 96, 105-116.

Kummer, H. \& Goodall, J. 1985. Conditions of innovative behaviour in primates. Philosophical Transactions of the Royal Society of London, Series B, 308, 203-214.

Laland, K. N. \& Plotkin, H. C. 1990. Social learning and social transmission of digging for buried food in Norway rats. Animal Learning and Behavior, 18, 246-251.

Laland, K. N. \& Williams, K. 1997. Shoaling generates social learning of foraging information in guppies. Animal Behaviour, 53, 1161-1169.

Lee, P. C. 1991. Adaptations to environmental change: an evolutionary perspective. In: Primate Responses to Environmental Change (Ed. by H. O. Box), pp. 39-56. London: Chapman \& Hall.

Lefebvre, L., Whittle, P., Lascaris, E. \& Finkelstein, A. 1997. Feeding innovations and forebrain size in birds. Animal Behaviour, 53, 549-560.

Lloyd Morgan, C. 1912. Instinct and Experience. London: Methuen. McDougall, W. 1936. An Outline of Psychology. 7th edn. London: Methuen.

McFarland, D. (Ed.) 1981. The Oxford Companion to Animal Behaviour. Oxford: Oxford University Press.

McGrew, W. C. 1979. Evolutionary implications of sex differences in chimpanzee predation and tool use. In: The Great Apes (Ed. by D. Hamburg \& E. M. McCown), pp. 441-464. Menlo Park, California: Benjamin/Cummins.

McGrew, W. C. 1994. Tools compared: the material of culture. In: Chimpanzee Culture (Ed. by R. W. Wrangham, W. C. McGrew, F. B. M. de Waal \& P. G. Heltne), pp. 25-39. Cambridge, Massachusetts: Harvard University Press.

Magurran, A. E. \& Seghers, B. H. 1994. Sexual conflict as a consequence of ecology: evidence from guppy, Poecilia reticulata, populations in Trinidad. Proceedings of the Royal Society of London Series $B, 255,31-36$.

Magurran, A. E., Seghers, B. H., Carvalho, G. R. \& Shaw, P. W. 1993. Evolution of adaptive variation in antipredator behaviour. Marine Behaviour and Physiology, 23, 29-44.

Magurran, A. E., Seghers, B. H., Shaw, P. W. \& Carvalho, G. R. 1995. The behavioural diversity and evolution of the guppy, Poecilia reticulata, populations in Trinidad. Advances in the Study of Behavior, 24, 155-202.

Mainardi, D. 1980. Social transmission of behavior in animals. In: Sociobiology: Beyond Nature/Nurture? (Ed. by G. Barlow \& I. Silverberg), pp. 227-255. Boulder, Colorado: Westview Press.

Mikheev, V. N., Metcalfe, N. B., Huntingford, F. A. \& Thorpe, J. E. 1994. Size-related differences in behaviour and spatial distribution of juvenile Atlantic salmon in a novel environment. Journal of Fish Biology, 45, 379-386. 
Milinski, M. 1993. Predation risk and feeding behaviour. In: Behaviour of Teleost Fishes. 2nd edn (Ed. by T. J. Pitcher), pp. 285-306. London: Chapman \& Hall.

Oikawa, S. \& Itazawa, Y. 1992. Relationship between metabolic rate invitro and body mass in a marine teleost, Porgy pagrus-major. Fish Physiology and Biochemistry, 10, 177-182.

Pedersen, B. H. 1997. The cost of growth in young fish larvae, a review of new hypotheses. Aquaculture, 155, 259-269.

Reznick, D. \& Yang, A. P. 1993. The influence of fluctuating resources on life-history-patterns of allocation and plasticity in female guppies. Ecology, 74, 2011-2019.

Sargent, R. C. \& Gross, M. R. 1993. Williams' principle: an explanation of parental care in teleost fishes. In: Behaviour of Teleost Fishes. 2nd edn (Ed. by T. J. Pitcher), pp. 333-361. London: Chapman \& Hall.

Sigg, H. 1980. Differentiation of female positions in hamadryas one-male units. Zeitschrift für Tierpsychologie, 53, 265-302.
Thorpe, W. H. 1956. Learning and Instinct in Animals. London: Methuen.

Visalberghi, E. \& Fragaszy, D. 1990. Do monkeys ape? In: Language and Intelligence in Monkeys and Apes (Ed. by S. T. Parker \& K. R. Gibson), pp. 247-273. Cambridge: Cambridge University Press.

Weinrich, M. T., Schilling, M. R. \& Belt, C. R. 1992. Evidence for acquisition of a novel feeding behaviour: lobtail feeding in humpback whales, Megaptera novaeangliae. Animal Behaviour, 44, 1059-1072.

Wilson, E. O. 1975. Sociobiology. Cambridge, Massachusetts: Harvard University Press.

Wyles, J. S., Kunkel, J. G. \& Wilson, A. C. 1983. Birds, behavior and anatomical evolution. Proceedings of the National Academy of Sciences U.S.A., 80, 4394-4397. 